\title{
MULTIPLICAÇÃO IN VITRO E ALONGAMENTO DAS BROTAÇÕES MICROPROPAGADAS DO PORTA-ENXERTO 'TSUKUBA 1'(Prunus persica L.) ${ }^{1}$
}

\author{
ELIZETE BEATRIZ RADMANN², VALMOR JOÃO BIANCHI ${ }^{3}$, \\ ROBERTO PEDROSO DE OLIVEIRA ${ }^{4}$, JOSÉ CARLOS FACHINELLO 5
}

RESUMO - Objetivou-se avaliar o efeito da fonte e concentração de citocinina e da composição dos sais presentes no meio de cultivo, na multiplicação in vitro do porta-enxerto 'Tsukuba 1' (Prunus persica L.). Explantes cultivados em meio QL/MS com 2,0 mg L-1 de BAP apresentaram maior formação de brotações e crescimento destas. Porém, é necessária a transferência dos explantes para o meio de cultura com redução na concentração de $\operatorname{BAP}\left(0,5 \mathrm{mg} \mathrm{L}^{-1}\right)$ para as brotações adquirirem tamanho adequado para a fase de enraizamento.

Termos para indexação: Pessegueiro, BAP, sais, explante, micropropagação.

\section{IN VITRO MULTIPLICATION AND ELONGATION OF THE MICROPROPAGATION SHOOTS OF THE ROOSTOCK OF 'TSUKUBA 1' (Prunus persica L.)}

\begin{abstract}
The objective was to assess the font and concentration's effect of cytokinin and salt composition, present in the medium of cultivation, on in vitro multiplication of the rootstock 'Tsukuba 1' (Prunus persica L.). Explants cultivated in QL/MS medium enriched with $2.0 \mathrm{mg} / \mathrm{L}$ of BAP showed more shoot formation and growth. However, it is necessary to transfer the explants to culture medium with reduced BAP concentration $(0.5 \mathrm{mg} / \mathrm{L})$, so that shoots may obtain the properly size for the rooting phase. Index terms: Peach, BAP, salts, explant, micropropagation.
\end{abstract}

\section{INTRODUÇÃO}

Técnicas baseadas na micropropagação de plantas podem ser empregadas com sucesso para propagação massal, sendo uma ferramenta útil para muitas espécies de importância econômica, produzindo plantas idênticas. No entanto, para o gênero Prunus, tem-se verificado progresso com relação à propagação in vitro para determinados genótipos, especialmente os de ameixeira (Leontiev-Orlov et al., 2000; Rodrigues et al., 2003) e do híbrido GF 677 (Battistini \& Paoli, 2002). Para P. pérsica, essa técnica deve ser aperfeiçoada porque existem dificuldades, tanto na fase de estabelecimento a partir do uso de meristemas, como nas fases de multiplicação e de enraizamento. No que se refere à etapa de multiplicação, tem-se verificado, em diversos trabalhos, uma variabilidade grande na taxa de brotação, com pouco crescimento das brotações formadas (Rocha, 2006; Silva, 2004; Channuntapipat et al., 2003; Matias, 1995).

A elevada variabilidade no comportamento de espécies lenhosas in vitro, em especial do gênero Prunus, faz com que seja necessário escolher condições de cultivo para cada espécie e para os diferentes genótipos. Portanto, a escolha adequada do meio de cultura é um fator relevante, devido ao importante papel dos componentes minerais no processo de multiplicação (Ramage \& Williams, 2002). Além da composição salina do meio de cultura, os reguladores de crescimento, principalmente as citocininas, exercem papel importante, pois estas são responsáveis pela indução de brotações axilares, pela redução da superação da dominância apical. Diante do exposto, neste trabalho, objetivou-se estudar a influência da fonte e concentração de citocinina e da composição

\footnotetext{
(Trabalho 198-08). Recebido em: 28-07-2008. Aceito para publicação em: 13-01-2009. Parte da Tese de Doutorado do primeiro autor.

${ }^{2}$ Eng. Agr. Dra. Bolsista CNPq/PDJ - FAEM/UfPel. R.Senador Mendonça, n.467, ap.401, 96015-200, Pelotas-RS. E-mail: eradmann@gmail.com (Autor para correspondência).

${ }^{3}$ Eng. Agr. Dr. Prof. Adjunto do Instituto de Biologia da UFPel. Campus Universitário s/n, Caixa postal 354, Cep 96010-900, PelotasRS. E-mail: valmorjb@yahoo.com.br.

${ }^{4}$ Eng. Agr. Dr. Pesquisador da Embrapa Clima Temperado. BR 392, km 78, C.P. 403, Cep 96001-970, Pelotas-E-mail: rpedroso@cpact.embrapa.br.

${ }^{5}$ Eng. Agr. Dr. Prof. Adjunto Dep. Fitotecnia da FAEM/UFPel. Campus Universitário s/n, Caixa postal 354, Cep 96010-900, PelotasRS. E-mail: jfachi@ufpel.the.br.
} 
dos sais presentes no meio de cultivo, na multiplicação in vitro do porta-enxerto 'Tsukuba 1' (Prunus persica L.).

\section{MATERIAL E MÉTODOS}

O presente trabalho foi conduzido na casa de vegetação da UFPel e no Laboratório de Cultura de Tecidos da Embrapa Clima Temperado, no período de abril de 2005 a dezembro de 2006. As plantas-matrizes de 'Tsukuba 1', destinadas para a multiplicação in vitro, foram previamente enxertadas sob a cultivar Capdeboscq, em abril de 2005. Após o início da brotação, as plantas foram transferidas para casa de vegetação, com objetivo de reduzir a contaminação in vitro. Além disso, realizou-se o pré-tratamento fitossanitário com bactericida (agrimicina 2,4 $\mathrm{g} \mathrm{L}^{-1}$ ) e fungicida (Captan 1,0 $\mathrm{g} \mathrm{L}^{-1}$ ), a cada três dias. Microestacas com $1 \mathrm{~cm}$, contendo uma gema, foram estabelecidas em tubos de ensaio, contendo meio MS, com $75 \%$ dos sais, mioinositol (100 mg L-1), sacarose $\left(30 \mathrm{~g} \mathrm{~L}^{-1}\right)$ e ágar $\left(6 \mathrm{~g} \mathrm{~L}^{-1}\right)$, com $\mathrm{pH} 5$,9. A partir do estabelecimento in vitro, procedeu-se aos trabalhos de multiplicação, os quais foram conduzidos em quatro experimentos, conforme segue.

\section{citocinina}

a) Efeito da fonte e da concentração de

Brotações com 1,0 cm, oriundas da fase de estabelecimento in vitro, foram inoculadas em meio MS com redução de $50 \%$ das fontes de nitrogênio. Foram testadas duas fontes de citocinina (2iP e BAP) nas concentrações 0,$0 ; 0,25 ; 0,5 ; 0,75$ e $1,0 \mathrm{mg} \mathrm{L}^{-1}$. A estes tratamentos, foram adicionados as vitaminas do meio MS, $100 \mathrm{mg} \mathrm{L}^{-1}$ de mioinositol, $30 \mathrm{~g} \mathrm{~L}^{-1}$ de sacarose, $0,01 \mathrm{mg} \mathrm{L}^{-1}$ de AIB e $6,0 \mathrm{~g} \mathrm{~L}^{-1}$ de ágar, com pH 5,9. Em seguida da inoculação, os explantes foram transferidos para sala de crescimento com temperatura de $25 \pm 2^{\circ} \mathrm{C}$, fotoperíodo de 16 horas e densidade de fluxo luminoso de $20 \mu \mathrm{mol} \mathrm{m}^{-2} \mathrm{~s}^{-1}$. Após 40 dias, avaliaram-se a porcentagem de brotação e o número de brotações por explante.

\section{BAP}

b) Efeito do aumento na concentração de

Com a finalidade de aumentar a proliferação in vitro do porta-enxerto 'Tsukuba 1', brotações apicais com $1,0 \mathrm{~cm}$ foram inoculadas em concentrações maiores de BAP $\left(0,0 ; 1,0 ; 2,0 ; 3,0\right.$ e $\left.4,0 \mathrm{mg} \mathrm{L}^{-1}\right)$. A composição básica do meio, bem como as condições de cultivo e as variáveis analisadas foram as mesmas do experimento anterior.

c) Efeito da composição do meio

Este estudo foi conduzido em dois experimentos. c1) No primeiro, o objetivo foi avaliar diferentes meios na multiplicação, conforme segue: MS ( $1 / 2$ das fontes de nitrogênio), WPM, QL e QL/MS (com macronutrientes do meio QL e micronutrientes do meio MS). Para isso, cada meio básico foi suplementado com as vitaminas do meio MS, 2, $0 \mathrm{mg} \mathrm{L}^{-1} \mathrm{de}$ BAP, $0,01 \mathrm{mg} \mathrm{L}^{-1}$ de AIB, $100 \mathrm{mg} \mathrm{L}^{-1}$ de mioinositol, $30 \mathrm{~g} \mathrm{~L}^{-1}$ de sacarose e $6,0 \mathrm{~g} \mathrm{~L}^{-1}$ de ágar, e $\mathrm{pH} 5,9$. Brotações apicais com $1,0 \mathrm{~cm}$ foram inoculadas nos respectivos tratamentos, sendo os mesmos mantidos em sala de crescimento com as mesmas condições de cultivo do experimento (a), por 40 dias. Posteriormente, analisaram-se as seguintes variáveis: porcentagem de brotação, de vitrificação e de crescimento das brotações, bem como número de brotações por explante e comprimento das mesmas.

c2) No segundo, os explantes com as respectivas brotações foram transferidos para a mesma composição básica, porém, com redução na concentração de BAP $\left(0,5 \mathrm{mg} \mathrm{L}^{-1}\right)$, com o objetivo de avaliar o crescimento das brotações obtidas no experimento c1. Analisou-se o crescimento das brotações em intervalo de 15 dias, ou seja, com 15; 30 e 45 dias, avaliando-se a porcentagem de crescimento das brotações e o seu comprimento.

Delineamento experimental e análise estatística

O delineamento experimental adotado para todos os experimentos, foi inteiramente casualizado, com cinco repetições, sendo cada repetição composta por um frasco com quatro explantes. Os dados do primeiro experimento (a) foram avaliados em esquema fatorial, com dois níveis do fator citocinina (BAP e 2iP) e cinco níveis do fator concentração $(0,0$; 0,$25 ; 0,5 ; 0,75$ e $\left.1,0 \mathrm{mg} \mathrm{L}^{-1}\right)$. O segundo (b), terceiro (c1) e quarto experimentos (c2) foram compostos por apenas um fator de tratamento, concentração de BAP com cinco níveis $(0,0 ; 1,0 ; 2,0 ; 3,0$ e 4,0 $\mathrm{mg} \mathrm{L}^{-1}$ ) para o segundo experimento (b) e meio de cultura com quatro níveis (MS 1/2, QL, QL/MS e WPM) para o terceiro e quarto experimentos. Os dados foram submetidos à análise de variância, e as médias, comparadas pelo teste de Duncan para os fatores citocinina e meio de cultura, e regressão polinomial para o fator concentração de BAP, com $5 \%$ de probabilidade.

\section{RESULTADOS E DISCUSSÃO}

\section{citocinina \\ a) Efeito da fonte e da concentração de \\ $\mathrm{Na}$ comparação entre as fontes de citocinina, observou-se que os tratamentos com 2 iP não respon- deram à formação de brotações adventícias, mesmo}


na concentração mais alta estudada. A adição de BAP ao meio de cultivo resultou em uma tendência linear crescente, com maior resposta na concentração de $1,0 \mathrm{mg} \mathrm{L}^{-1}$, com 34,8\% de explantes brotados (Figura 1A) e, em média, 1,25 brotação por explante (Figura 1B). Esses resultados podem ser atribuídos ao maior efeito citocinínico do BAP, em relação ao 2iP. Essa resposta pode ser devida ao fato de que a enzima citocinina oxidase dos tecidos degrada o $2 \mathrm{iP}$, por meio do rompimento da ligação da cadeia lateral da molécula (Barrueto Cid, 2000). Em consequência, a ausência da indução de brotação, ou os baixos índices de multiplicação, são obtidos com esta citocinina.

Observações similares à do presente trabalho foram obtidas por Turk \& Siftar (1992) e por Vasar et al. (1998), estudando a resposta destas duas citocininas em ameixeira ( $P$. domestica), os quais relataram que, mesmo com a adição de $10 \mathrm{mg} \mathrm{L}^{-1}$ de $2 \mathrm{iP}$ ao meio de cultura, a multiplicação dos explantes não foi afetada. Em estudo realizado com caquizeiro, Telles \& Biasi (2005) também constataram que meios suplementados com 2iP apresentaram piores resultados, responderam de maneira inferior quando comparados com a zeatina.

De acordo com Barrueto Cid (2000), o BAP é a citocinina sintética de menor custo, em relação às demais fontes deste regulador de crescimento, sendo a mais ativa e mais utilizada na multiplicação de diversas espécies. A razão de sua maior eficiência pode estar na capacidade dos tecidos vegetais em metabolizar reguladores de crescimento naturais (2iP) mais rapidamente do que os sintéticos (BAP) (Santos-Serejo et al., 2006).

Embora as concentrações com 0,75 e 1,0 mg $\mathrm{L}^{-1}$ de BAP tenham sido superiores aos tratamentos com $2 \mathrm{iP}$ (Figuras 1A e 1B), as respostas foram baixas, quando comparados com outros trabalhos (Liberali \& Damiano, 1998; Couto et al., 2004; Rogalski et al., 2003), sendo as brotações caracterizadas como pequenas, pouco desenvolvidas e sem crescimento. Este fato pode estar relacionado com a cultivar estudada, pois normalmente cada genótipo responde de forma distinta. Grattapaglia \& Machado (1998) relatam que algumas espécies são mais difíceis de multiplicar do que outras, necessitando, às vezes, da adição de citocinina em maiores concentrações. Portanto, conduziu-se o segundo experimento com o objetivo de avaliar o efeito no aumento da concentração de BAP.

\section{b) Efeito do aumento na concentração de}

\section{BAP}

Observou-se um aumento na multiplicação dos explantes com incremento de BAP, sendo que, pela estimativa da equação de regressão, a resposta foi positiva até $3,0 \mathrm{mg} \mathrm{L}^{-1}$, com $54,7 \%$ de explantes brotados (Figura 1C), e até $2,87 \mathrm{mg} \mathrm{L}^{-1}$ para o número de brotações por explante (1,99) (Figura 1D). A partir dessas concentrações, houve decréscimo na resposta para estas variáveis. Porém, as brotações formadas continuaram sem crescimento. Embora a resposta quadrática para essas variáveis inferisse pontos de máxima em torno de $3,0 \mathrm{mg} \mathrm{L}^{-1}$, observou-se que a adição de 2,0 $\mathrm{mg} \mathrm{L}^{-1}$ apresentou os maiores valores numéricos para as variáveis avaliadas, comparativamente às demais concentrações avaliadas. Respostas similares foram encontradas por Rogalski et al. (2003), com a ameixeira 'Santa Rosa', os quais obtiveram maior número de brotações, com 2,0 mg $\mathrm{L}^{-1}$ de BAP, porém esta concentração permitiu a formação de 3,6 brotações, 1,54 broto a mais do que no presente trabalho. Já, para a cultivar ' $M r$. S 2/5', Rocha (2006) obteve 1,6 brotação por explante com a adição exógena de $2,0 \mathrm{mg} \mathrm{L}^{-1}$ de BAP. Por outro lado, Rodrigues et al. (2003) obtiveram em torno de duas brotações por explante, com apenas $0,7 \mathrm{mg} \mathrm{L}^{-1}$ de BAP para as cultivares Aldrighi, Eldorado, GF 677 e Okinawa.

Nem sempre o acréscimo de citocinina exógena no meio de cultura aumenta o número de brotações formadas, podendo levar à formação de desordens fisiológicas como a vitrificação dos explantes e a redução no crescimento das brotações. A menor exigência de citocinina para determinados genótipos pode estar associada aos altos teores endógenos, que aliados à adição deste regulador de crescimento ao meio de cultura, pode contribuir para um efeito decrescente na taxa de multiplicação. Este efeito normalmente é observado na multiplicação in vitro de genótipos de ameixeira, comprovado pelos trabalhos de Leontiev-Orlov et al. (2000), Campos (2005) e Rocha (2006). Com base nesses relatos, fica clara a influência do genótipo, sendo a multiplicação in vitro de plantas do subgênero Prunophora menos problemática do que as plantas do subgênero Amygdalus.

Por conseguinte, associando as respostas do presente trabalho com os dados da literatura, constata-se que cada genótipo apresenta exigências diferentes, necessitando, portanto, a modificação na composição do meio de cultura conforme o genótipo a ser trabalhado. Desta forma, o próximo estudo foi conduzido com a finalidade de verificar a influência da concentração de sais na multiplicação in vitro do porta-enxerto 'Tsukuba 1'.

\section{c) Efeito da composição do meio}

c1) A maior porcentagem de brotação foi observada nos meios MS e QL, que foram superiores em 20\%, com relação aos demais meios testados (Ta- 
bela 1). Porém, esses meios também apresentaram 20 e $25 \%$ de explantes vitrificados, anomalia esta não observada nos meios QL/MS e WPM (Tabela 1). Já com relação ao número de brotações, não se observou diferença significativa entre os meios (Tabela 1). Quanto ao comprimento das brotações formadas, os maiores valores foram observados no meio QL, com uma média de $51 \%$ de crescimento (Tabela 1) e comprimento médio das brotações de $0,33 \mathrm{~cm}$ (Tabela 1$)$.

Resultado similar ao do presente trabalho foi encontrado por Chaves (2003), ou seja, não observou efeito significativo para a variável número de brotações, entre o meio mais concentrado (MS) e o meio com menor concentração de sais (WPM), para as cvs. Mr. S 1/8 e Okinawa. Mas, as brotações formadas com 'Mr.S 1/8' foram maiores no WPM $(1,0 \mathrm{~cm})$ e aquelas oriundas de 'Okinawa' cresceram mais no MS $(0,9 \mathrm{~cm})$. Porém, Harada \& Murai (1996) revelaram superioridade do meio WPM ao MS com Prunus mume. Matias (1995) constatou que o meio mais concentrado (MS) foi significativamente superior ao WPM, para o número de brotações formadas, bem como para o crescimento destas, para as cultivares Flordaprince e Diamante. No entanto, o número de brotações foi inferior ao obtido no presente trabalho, 1,62 e 1,12, mas superior em relação ao tamanho das brotações formadas, com 0,54 e $0,27 \mathrm{~cm}$, nos meios MS e WPM, respectivamente. Rocha (2006) obteve maior comprimento de brotação em meio MS quando comparado ao meio com sais reduzidos (QL), com 1,2 cm para o portaenxerto 'Síri.,o' e 0,7 cm para 'Mr. S. 2/5'. Porém, a porcentagem de brotação e o número de brotações formadas não foram influenciados estatisticamente pela concentração de sais.

A vitrificação de alguns explantes que ocorreu no meio MS (Tabela 1), provavelmente, está associada à maior concentração salina, principalmente a de nitrato de amônia que, apesar da redução de $50 \%$ utilizada neste trabalho, continua sendo superior aos demais meios em 50\%. Segundo Grattapaglia \& Machado (1998), a redução da concentração da fonte de nitrogênio na forma amoniacal tem sido utilizada para reduzir a vitrificação. Contudo, também se verificaram explantes vitrificados em meio QL. A anomalia nestes explantes pode estar relacionada à relação macro/micronutrientes, pois esta é maior no meio QL e menor no meio QL/MS, onde não foi constatada esta anormalidade.

c2) Após a passagem dos explantes para meios com redução na concentração de BAP, a análise de variância mostrou que houve diferença significativa entre os meios testados. No entanto, o efeito significativo entre os tratamentos, para a variável porcentagem de crescimento das brotações, verificouse apenas nos primeiros 15 dias de avaliação, sendo o meio QL/MS superior aos demais (84\%) (Figura 2A). Já no comprimento das brotações, observou-se diferença significativa aos 45 dias, sendo QL/MS o meio que proporcionou o maior crescimento, com uma média de 2,25 cm (Figura 2B).

Pelos resultados obtidos no presente trabalho, constatou-se que a passagem para o meio de cultura com redução na concentração de BAP foi eficiente no crescimento das brotações formadas, para todos os tratamentos testados (Figuras 2A, 2B e 3). Estes resultados corroboram Grattapaglia \& Machado (1998), os quais relatam que a transferência das culturas para meio básico, diluído ou não, com concentrações reduzidas ou ausentes de citocinina, promove o crescimento das brotações, antes de individualizá-las para a fase de enraizamento. Entretanto, Pérez-Tornero et al. (2000) salientam que a composição do meio de cultura também pode influenciar no crescimento dos explantes. Esta diferença pode ser comprovada no presente estudo, embora tenha havido crescimento de $100 \%$ das brotações em todos os tratamentos, e a composição salina QL/MS revelou ser superior aos demais meios aos 45 dias. Este resultado concorda com Silva (2004), que constatou que o meio QL/MS incrementou significativamente o comprimento das brotações para a ameixeira cultivar América.

Segundo os dados deste estudo, o tempo de permanência dos explantes no meio de indução de brotações é fator importante para o crescimento das mesmas, visto que o tamanho das brotações oriundas da fase de multiplicação é fator determinante para a etapa de enraizamento. Sendo assim, constatou-se que, com 15 dias, os brotos não estão com tamanho apropriado para o enraizamento, pois atingiram apenas $0,67 \mathrm{~cm}$. Por outro lado, com 30 e 45 dias, as brotações já estariam aptas, quando atingem 1,54 e $2,25 \mathrm{~cm}$ de altura, respectivamente, ou seja, com tamanho adequado para a fase de enraizamento. 

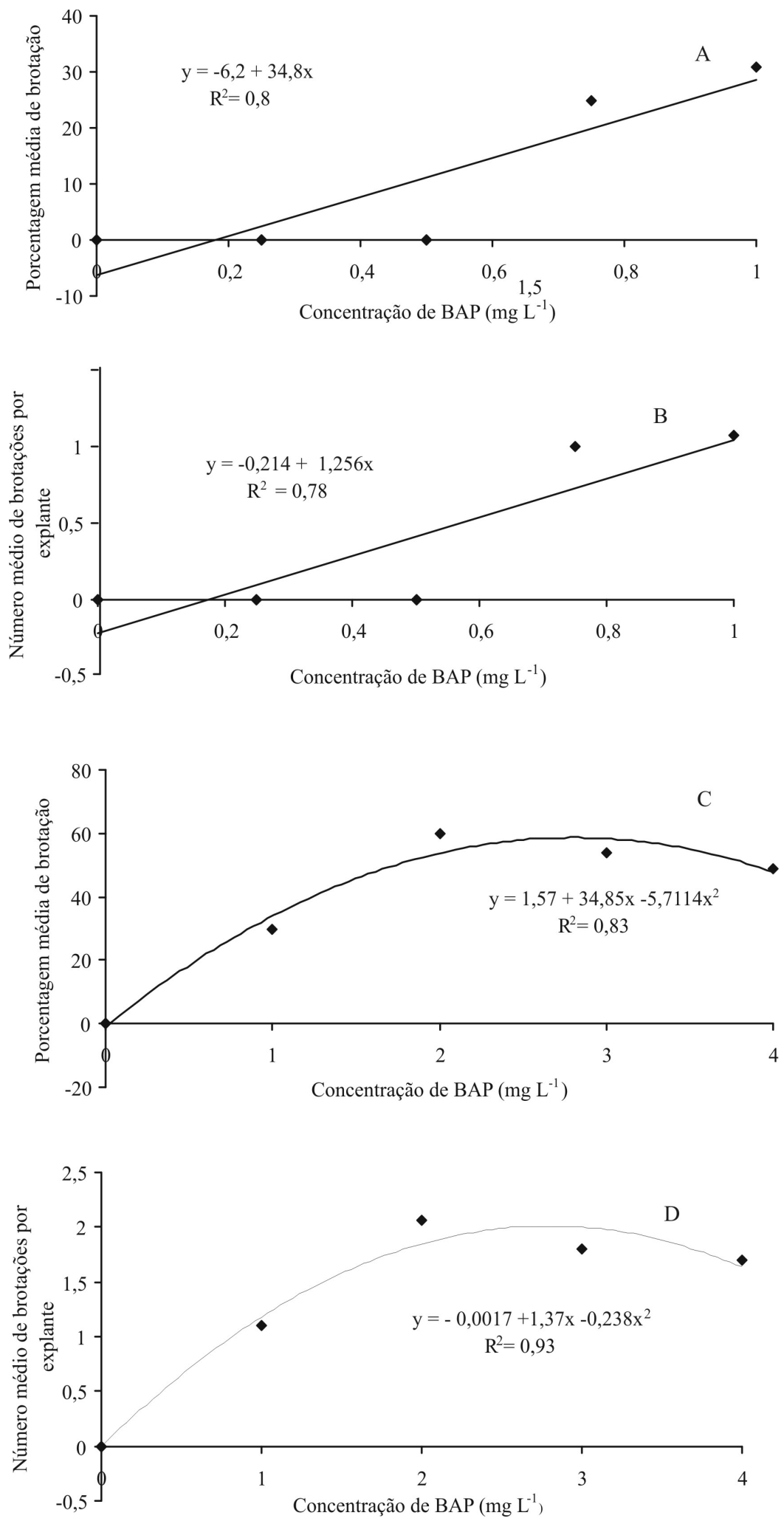

FIGURA 1 - Porcentagem média de brotação (A e C) e número médio de brotações por explante (B e D) obtidos com o porta-enxerto 'Tsukuba 1', em meio de cultivo acrescido por diferentes concentrações de BAP. 

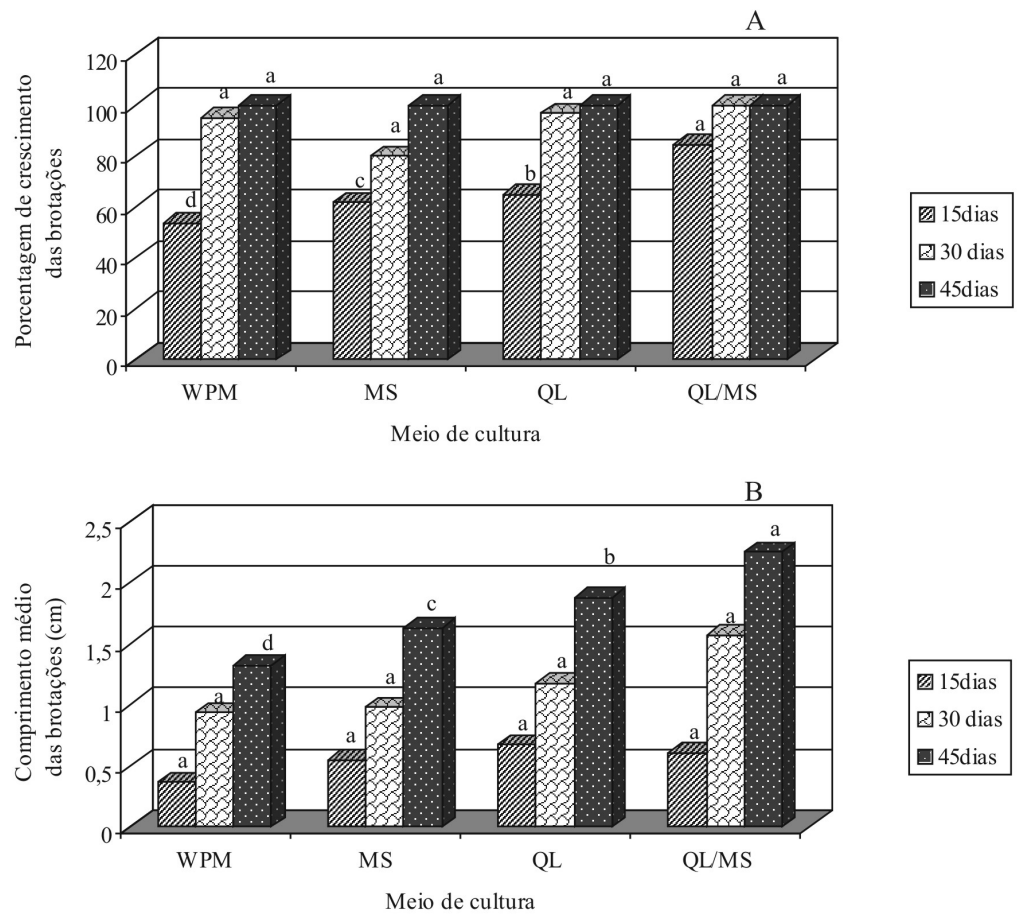

\begin{tabular}{|l|}
\hline 짐 \\
$\square 30$ dias \\
$\square 45$ dias
\end{tabular}

FIGURA 2 - Porcentagem de crescimento das brotações (A) e comprimento das mesmas (B), com o portaenxerto 'Tsukuba 1', em diferentes meios de cultura, com redução na concentração de BAP para $0,5 \mathrm{mg} \mathrm{L}^{-1}$, avaliado aos $15 ; 30$ e 45 dias. Médias seguidas de mesma letra minúscula não diferem entre si, para o fator meio de cultura, dentro de cada data de avaliação.

A

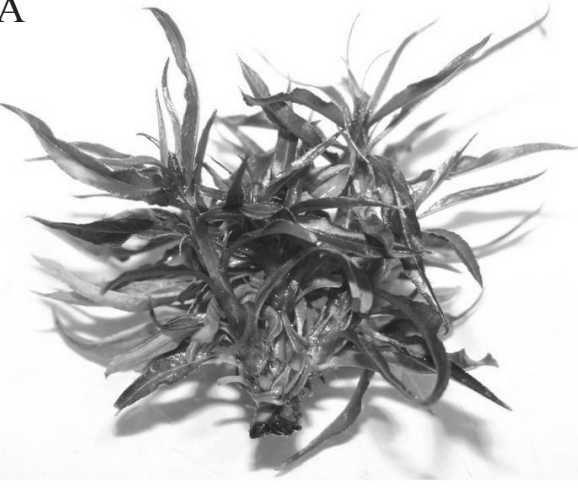

$\mathrm{C}$

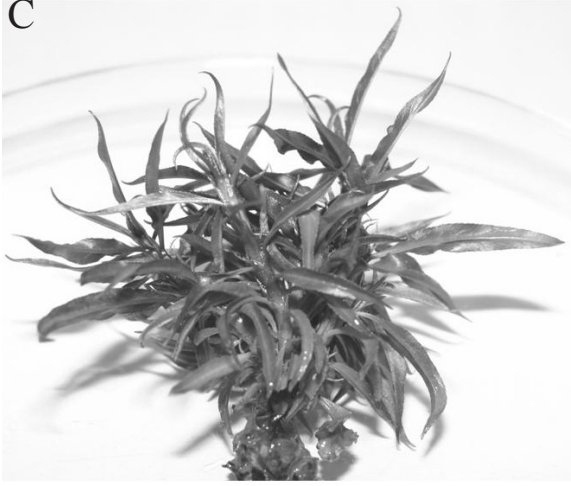

B

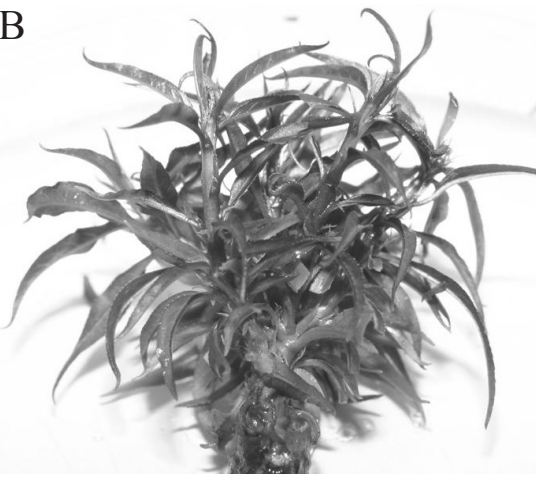

$\mathrm{D}$

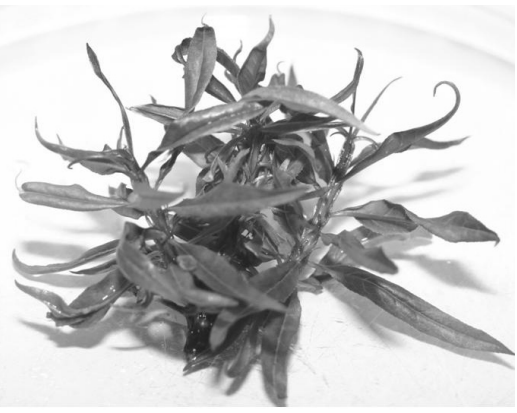

FIGURA 3 - Aspecto das brotações provenientes de explantes com o porta-enxerto 'Tsukuba 1', cultivados em diferentes meios WPM (A), QL/MS (B), QL (C) e MS (D), com redução na concentração de BAP para $0,5 \mathrm{mg} \mathrm{L}^{-1}$. 
TABELA 1 - Porcentagem de brotações, de vitrificação e de crescimento das brotações, número de brotações por explante e comprimento das brotações, obtidas com o porta-enxerto 'Tsukuba 1', em diferentes meios de cultura

\begin{tabular}{|c|c|c|c|c|c|}
\hline $\begin{array}{l}\text { Meio de } \\
\text { cultura }\end{array}$ & $\begin{array}{c}\text { Brotações } \\
(\%)\end{array}$ & $\begin{array}{c}\text { Vitrificação } \\
(\%)\end{array}$ & $\begin{array}{c}\text { Número de } \\
\text { brotações }\end{array}$ & $\begin{array}{c}\text { Crescimento das } \\
\text { brotações (\%) }\end{array}$ & $\begin{array}{l}\text { Comprimento das } \\
\text { brotações }(\mathrm{cm})\end{array}$ \\
\hline MS & $100 \mathrm{a}$ & $20 a$ & $3,4 \mathrm{a}$ & $43 \mathrm{~b}$ & $0,29 \mathrm{~b}$ \\
\hline QL & $100 \mathrm{a}$ & $25 \mathrm{a}$ & $4,0 \mathrm{a}$ & $51 \mathrm{a}$ & $0,33 \mathrm{a}$ \\
\hline QL/MS & 80 & $\mathrm{~b}$ & $3,6 \mathrm{a}$ & $44 \mathrm{~b}$ & $0,30 \mathrm{~b}$ \\
\hline WPM & 80 & $\mathrm{~b}$ & $3,5 \mathrm{a}$ & 0 & 0,00 \\
\hline
\end{tabular}

${ }^{1}$ Médias seguidas de mesma letra minúscula não diferem entre si, para o fator meio de cultura.

\section{CONCLUSÕES}

Nas condições em que o trabalho foi conduzido, pode-se concluir que:

1- Nas concentrações testadas, o BAP é mais eficiente do que o $2 \mathrm{iP}$.

2- Meio de cultura com 2,0 $\mathrm{mg} \mathrm{L}^{-1}$ de BAP é suficiente para a multiplicação in vitro.

3- Maior multiplicação e crescimento das brotações são obtidos com o meio QL/MS.

\section{REFERÊNCIAS}

BARRUETO CID, L.P. Citocininas. In: BARRUETO CID, L.P. Introdução aos hormônios vegetais. 1.ed. Brasília: Embrapa Recursos Genéticos e Biotecnologia, 2000. p.55-81.

BATTISTINI, A.; PAOLI, G. Large scale micropropagation of several peach rootstocks. Acta Horticulturae, The Hague, v.592, p.123-127, 2002.

CAMPOS, R.V. Estabelecimento, multiplicação e enraizamento in vitro de porta-enxertos de Prunus spp. 2005. 67f. Dissertação (Mestrado em Agronomia) - Universidade Federal de Pelotas, 2005.

CHANNUNTAPIPAT, C.; SEDGLEY, M.; COLLINS, G. Micropropagation of almond cultivars Nonpareil and Ne Plus Ultra and the hybrid rootstock Titan x Nemaguard. Scientia Horticulturae, Amsterdan, v. 98, p.473-484, 2003.

CHAVES, A.C. Micropropagação de portaenxertos para fruteiras de caroço. 2003. 59f. Dissertação (Mestrado em Agronomia) - Universidade Federal de Pelotas, 2003.

COUTO, M.; OLIVEIRA, R.P.; FORTES, G.R.L. de. Multiplicação in vitro dos porta-enxertos de Prunus sp. cv. Barrier e Cadman. Revista Brasileira de Fruticultura, Jaboticabal, v.26, n.1, p.5-7, 2004.

GRATTAPAGLIA, D.; MACHADO, M.A. Micropropagação. In: TORRES, A.C.;CALDAS, L.S.; BUSO, J.A. Cultura de tecidos e transformação genética de plantas. 1. ed. Brasília: Embrapa-SPI/ Embrapa-CNPH, 1998. p.183-260.

HARADA, H.; MURAI, Y. Micropropagation of Prunus mume. Plant Cell Tissue and Organ Culture, The Hague, v.48, n.3, p.265-267, 1996.

LEONTIEV-ORLOV, O.; ROGALSKI, M.; MOSSI, A.J.; CANSIAN, R.L. 6-Benzilaminopurina (BAP) na multiplicação in vitro de prunáceas (Prunus sp.). Revista Brasileira de Agrociência, Pelotas, v.6, n.1, p.63-67, 2000.

LIBERALI, M.; DAMIANO, C. Propagazione in vitro del portinnesto citation ibrido susino per pesco. In: GIORNATE SCIENTICHE, 4, 1998, Roma. Annali dell' Istituto Sperimentale per la Frutticoltura-MIPA, Roma, p.27-28, 1998.

MATIAS, A.C. Estabelecimento e multiplicação de pessegueiro in vitro (Prunus persica L. Batsch) cultivares Flordprince e Diamante. 1995. 84f. Dissertação (Mestrado em Agronomia) - Universidade Federal de Pelotas, 1995.

PEREZ-TORNERO, O.; LOPEZ, J.M.; EGEA, J.; BURGOS, L. Effect of basal media and growth regulators on the in vitro propagation of apricot (Prunus armeniaca L.) cv. Canino. Journal of Horticultural Science \& Biotechnology, Ashfrord, v.75, n.3, p.283-286, 2000.

RAMGE, C.M.; WILLIAMS, R.R. Mineral nutrition and plant morphogenesis. In vitro Cellular \& Developmental Biology - Plant, Wallinghord, v.38, p.116-124, 2002. 
ROCHA, P.S.G. Propagação in vitro de portaenxertos do gênero Prunus spp. 2006. 101f. Tese (Doutorado em Agronomia) - Universidade Federal de Pelotas, 2006.

RODRIGUES, A.C.; SILVEIRA, C.A.P.; FORTES, G.R.de L.; FACHINELLO, J.C.; SILVA, J.B.da. Estabelecimento e multiplicação in vitro de Prunus sp em diferentes meios de cultura. Revista Brasileira de Fruticultura, Jaboticabal, v.25, n.1, p.131-133, 2003.

ROGALSKI, M.; GUERRA, M.P.; SILVA, A.L. Multiplicação in vitro da ameixeira 'Santa Rosa': Efeito da citocinina BAP. Revista Brasileira de Fruticultura, Jaboticabal, v. 25, n. 2, p.365-367, 2003.

SANTOS-SEREJO, J.A.; JUNGHANS, T.G.; SOARES, T.L.; SILVA, K.M. Meios nutritivos para micropropagação de plantas. In: SOUZA, A.S.; JUNGHANS, T.G. Introdução à micropropagação de plantas. 1.ed. Cruz das Almas: Embrapa Mandioca e Fruticultura Tropical, 2006. p.80-98.
SILVA, E.S.B. Propagação in vitro de Prunus spp. 2004. 115f. Tese (Doutorado em Agronomia) - Universidade Federal de Pelotas, 2004.

TELLES, C.A.; BIASI, L.A. Organogênese do caquizeiro a partir de ápices meristemáticos, segmentos radiculares e foliares. Acta Scientiarum Agronomy, Maringá, v.27, n.4, p.581-586, 2005.

TURK, B.A.; SIFTAR, J.S. Micropropagation of the plum ecotype (Prunus domestica L.) as rootstock for apricots. Acta Horticulturae, The Hague, v.1, p.58, 1992.

VASAR, V.; PAE, A.; JANES, H. Influence of nitrogen content and cytokinin source on Prunus domestica L. proliferation and elongation in vitro. Acta Horticulturae, The Hague, v.478, p.56, 1998. 